\title{
Mycoplasma genitalium infection: current treatment options, therapeutic failure, and resistance-associated mutations
}

This article was published in the following Dove Press journal:

Infection and Drug Resistance

26 May 2015

Number of times this article has been viewed

\author{
Deborah L Couldwell ${ }^{1,2}$ \\ David A Lewis ${ }^{1,2}$ \\ 'Western Sydney Sexual Health \\ Centre, Parramatta, ${ }^{2}$ Centre for \\ Infectious Diseases and Microbiology \\ and Marie Bashir Institute for \\ Infectious Diseases and Biosecurity, \\ Westmead Clinical School, University \\ of Sydney, Sydney, NSW, Australia
}

\begin{abstract}
Mycoplasma genitalium is an important cause of non-gonococcal urethritis, cervicitis, and related upper genital tract infections. The efficacy of doxycycline, used extensively to treat non-gonococcal urethritis in the past, is relatively poor for $M$. genitalium infection; azithromycin has been the preferred treatment for several years. Research on the efficacy of azithromycin has primarily focused on the $1 \mathrm{~g}$ single-dose regimen, but some studies have also evaluated higher doses and longer courses, particularly the extended $1.5 \mathrm{~g}$ regimen. This extended regimen is thought to be more efficacious than the $1 \mathrm{~g}$ single-dose regimen, although the regimens have not been directly compared in clinical trials. Azithromycin treatment failure was first reported in Australia and has subsequently been documented in several continents. Recent reports indicate an upward trend in the prevalence of macrolide-resistant $M$. genitalium infections (transmitted resistance), and cases of induced resistance following azithromycin therapy have also been documented. Emergence of antimicrobial-resistant M. genitalium, driven by suboptimal macrolide dosage, now threatens the continued provision of effective and convenient treatments. Advances in techniques to detect resistance mutations in DNA extracts have facilitated correlation of clinical outcomes with genotypic resistance. A strong and consistent association exists between presence of $23 \mathrm{~S}$ rRNA gene mutations and azithromycin treatment failure. Fluoroquinolones such as moxifloxacin, gatifloxacin, and sitafloxacin remain highly active against most macrolideresistant $M$. genitalium. However, the first clinical cases of moxifloxacin treatment failure, due to bacteria with coexistent macrolide-associated and fluoroquinolone-associated resistance mutations, were recently published by Australian investigators. Pristinamycin and solithromycin may be of clinical benefit for such multidrug-resistant infections. Further clinical studies are required to determine the optimal therapeutic dosing schedules for both agents to effect clinical cure and minimize the risk of emergent antimicrobial resistance. Continual inappropriate M. genitalium treatments will likely lead to untreatable infections in the future.
\end{abstract}

Keywords: Mycoplasma genitalium, non-gonococcal urethritis, macrolide, fluoroquinolone, resistance, treatment failure

\section{Introduction}

Mycoplasma genitalium is a cause of acute and chronic non-gonococcal urethritis (NGU) and cervicitis, and is increasingly implicated in upper genital tract infections. ${ }^{1,2}$ This minute genital parasite of the Mollicute class grows slowly as it is lacks the genes required for biosynthesis of amino acids and instead relies on host cells for nutrients. ${ }^{1}$ Despite its minute size, $M$. genitalium displays features in common with other pathogenic bacteria that enable it to cause disease, evade host immune responses through antigenic variability, and readily develop resistance to antimicrobial agents. ${ }^{3}$
Correspondence: David A Lewis Western Sydney Sexual Health Centre, Level 4 Jeffery House, 162 Marsden Street, Parramatta, NSW, Australia Email david.lewis2@sydney.edu.au 
Antimicrobial resistance is threatening the provision of effective, safe, and convenient treatment for $M$. genitalium, as well as a number of other bacterial sexually transmitted infections (STIs), such as gonorrhea. ${ }^{4,5}$ While the gonococcus has a lengthy and well documented evolutionary history in terms of acquisition of new antimicrobial resistance mechanisms, $M$. genitalium is developing resistance to macrolides and fluoroquinolones at a speed belying its small size and, rather unexpectedly, before the introduction of systematic testing and treatment protocols. Clinical and patient factors promoting antimicrobial resistance in STI pathogens are gathering pace, driving the intrinsic propensity of these organisms to acquire antimicrobial resistance determinants or DNA point mutations at alarming rapidity. ${ }^{4,6-8}$

\section{Management issues in the treatment of $M$. genitalium infections}

Syndromic treatment of NGU has focused on eradication of Chlamydia trachomatis, a well-established cause of reproductive morbidity in women, and is usually instituted at initial presentation before results of investigations to detect specific bacterial causes are made available. In most cases of sexually acquired urethritis and cervicitis, tests are only performed for Neisseria gonorrhoeae and C. trachomatis.

Few countries offer routine screening for M. genitalium and, where this is performed, it typically relies on the use of in-house nucleic acid amplification tests performed on specimens collected at either the initial visit or after failure of first-line therapy. Importantly, there are still no validated and commercially available assays for routine diagnostic testing although these may be available in the near future. ${ }^{9}$ While many experts accept current evidence linking $M$. genitalium with upper genital tract infections and infertility, a prospective observational study of morbidity associated with untreated $M$. genitalium infection would not be ethical in the light of current evidence. Doubts about the importance of $M$. genitalium as a reproductive pathogen, along with the lack of an approved diagnostic test, have delayed decisions on testing and treatment protocols. ${ }^{9,10}$

\section{Overview of natural history and prevalence of $M$. genitalium infection}

The natural history of $M$. genitalium infection in men with NGU has not been studied, but spontaneous clearance of infection occurred in $55 \%$ of a cohort of African women within 3 months. ${ }^{11}$ In the absence of systematic screening and on the basis of studies conducted where testing is available,
M. genitalium is most frequently detected in men who present with urethral symptoms. ${ }^{12}$ Prevalence rates of $15 \%-35 \%$ are reported in men with symptomatic non-chlamydial NGU, whereas estimates of population prevalence of $M$. genitalium range from $1.1 \%$ to $3.3 \%{ }^{13}$ Infections in women and anal infections among men-who-have-sex-with-men (MSM) are largely asymptomatic and therefore remain undiagnosed. ${ }^{2,14}$ A study among MSM at a London clinic found $M$. genitalium prevalence rates of $2.7 \%$ and $4.4 \%$ in first-void urine and rectal samples, respectively, with higher rates in human immunodeficiency virus (HIV)-positive versus HIV-negative MSM, suggesting that asymptomatic rectal infection is relatively common in this risk group. ${ }^{15}$ Finally, there is evidence that the prevalence of $M$. genitalium is increasing, at least in Scandinavia. A Danish national survey found that the proportion of those tested who tested positive increased significantly between the periods 2006-2008 and 2009-2010. ${ }^{13}$

\section{Current treatment options}

In common with other mycoplasmas, $M$. genitalium lacks a cell wall, and is therefore not susceptible to antibiotics targeting peptidoglycan assembly. Although tetracyclines, in particular doxycycline, have been used to treat NGU for many years, the efficacy of this antimicrobial class is relatively poor and isolates with reduced susceptibility have been reported. ${ }^{16-18}$ Azithromycin, a macrolide, is now preferred for the treatment of NGU and related clinical syndromes on account of its long half-life, excellent tissue penetration, and the fact that it can be administered as a single-dose treatment. Clinical studies in which $M$. genitalium testing and treatment results have been reported include observational studies and several randomized clinical trials; these are summarized in Tables 1 and 2. In most cases, research effort has focused on studying the effectiveness of a single $1 \mathrm{~g}$ dose of azithromycin. ${ }^{19-27}$ Studies have also reported the efficacy of higher doses and longer courses of azithromycin, particularly the extended $1.5 \mathrm{~g}$ course, given as $500 \mathrm{mg}$ on day 1 and then $250 \mathrm{mg}$ daily on days $2-5$, or less often, two $1 \mathrm{~g}$ doses given 5-7 days apart. ${ }^{17,24,26}$

A controlled but non-randomized clinical trial recruited STI clinic patients with urethritis or cervicitis from Norway and Sweden from 2002 to $2004 .^{20}$ Treatment was initiated with either doxycycline (200 mg on day 1, $100 \mathrm{mg}$ daily on days 2-9) or azithromycin $1 \mathrm{~g}$ as a single dose. Those who tested positive for $M$. genitalium were followed up, and if initial treatment failed, were treated with the alternative antibiotic, either azithromycin as an extended $1.5 \mathrm{~g}$ regimen (500 mg on day 1, $250 \mathrm{mg}$ daily on days $2-5$ ), or doxycycline 
Table I Clinical efficacy studies of tetracycline/doxycycline, alone or versus macrolides, for treatment of Mycoplasma genitalium infection

\begin{tabular}{|c|c|c|c|c|c|c|}
\hline Reference & Year & Study type & Population & $\begin{array}{l}\text { M. genitalium } \\
\text { cases }(\mathbf{n})\end{array}$ & $\begin{array}{l}\text { Tetracycline regimen(s) } \\
\text { and } M \text {. genitalium } \\
\text { microbiological cure }\end{array}$ & $\begin{array}{l}\text { Macrolide regimen } \\
\text { and } M \text {. genitalium } \\
\text { microbiological cure }\end{array}$ \\
\hline $\begin{array}{l}\text { Horner } \\
\text { et al }{ }^{10}\end{array}$ & 1993 & $\begin{array}{l}\text { Prospective } \\
\text { case-control } \\
\text { study }\end{array}$ & $\begin{array}{l}\text { I } 64 \text { men with/without } \\
\text { NGU attending an STI } \\
\text { clinic, UK }\end{array}$ & 27 men & $\begin{array}{l}\text { DOXY } 200 \mathrm{mg} \text { d I, } \\
100 \mathrm{mg} \text { d } 2-\mathrm{d} 9 \\
\text { 10/14 cured (7I.4\%) }\end{array}$ & Not applicable \\
\hline $\begin{array}{l}\text { Johannisson } \\
\text { et al }{ }^{18}\end{array}$ & 2000 & $\begin{array}{l}\text { Uncontrolled } \\
\text { observational } \\
\text { study }\end{array}$ & $\begin{array}{l}233 \text { men and } 85 \text { women } \\
\text { attending STI clinics, } \\
\text { Sweden }\end{array}$ & $\begin{array}{l}18 \text { men } \\
3 \text { women }\end{array}$ & $\begin{array}{l}\text { TET } 500 \mathrm{mg} \text { I } 2 \text { hourly } \times 10 \mathrm{~d} \\
5 / 13 \text { men cured }(38.5 \%) \\
0 / 1 \text { women cured }(0 \%)\end{array}$ & Not applicable \\
\hline $\begin{array}{l}\text { Gambini } \\
\text { et } \mathrm{al}^{19}\end{array}$ & 2000 & $\begin{array}{l}\text { Prospective study } \\
\text { with treatment } \\
\text { varying by room }\end{array}$ & $\begin{array}{l}20 I \text { men with/without NGU } \\
\text { attending an STI clinic, Italy }\end{array}$ & 53 men & $\begin{array}{l}\text { DOXY } 200 \mathrm{mg} / \text { day } \times 7 \mathrm{~d} \\
33 / 35 \text { cured }(94.3 \%)\end{array}$ & $\begin{array}{l}\text { AZM I g stat } \\
\text { I } 4 / 17 \text { cured }(82.4 \%)\end{array}$ \\
\hline Falk et al ${ }^{17}$ & 2003 & $\begin{array}{l}\text { Uncontrolled } \\
\text { observational } \\
\text { study }\end{array}$ & $\begin{array}{l}519 \text { men and } 464 \text { women } \\
\text { attending an STI clinic, } \\
\text { Sweden }\end{array}$ & $\begin{array}{l}34 \text { men } \\
26 \text { women }\end{array}$ & $\begin{array}{l}\text { DOXY } 200 \mathrm{mg} \text { d I, } 100 \mathrm{mg} \\
\text { d } 2-\mathrm{d} 9 \text { or LYME } 300 \mathrm{mg} \\
\text { I2 hourly } \times 10 \mathrm{~d} \\
\text { Men: } 6 / 16 \text { cured }(37.5 \%) \\
\text { Women: } 4 / 14 \text { cured }(28.6 \%)\end{array}$ & $\begin{array}{l}\text { AZM } 500 \mathrm{mg} \mathrm{d} \text { I, } 250 \mathrm{mg} \\
\text { d } 2-d \mathrm{~d} 5 \\
\text { Men: } 16 / 16 \text { cured (I00.0\%) } \\
\text { Women: } 20 / 20 \text { cured } \\
\text { (I00.0\%) }\end{array}$ \\
\hline $\begin{array}{l}\text { Björnelius } \\
\text { et } \mathrm{al}^{20}\end{array}$ & 2008 & $\begin{array}{l}\text { Uncontrolled } \\
\text { observational } \\
\text { study }\end{array}$ & $\begin{array}{l}\text { I52 men with NGU and } \\
60 \text { women with cervicitis } \\
\text { attending } 6 \text { STI clinics, } \\
\text { Norway and Sweden }\end{array}$ & $\begin{array}{l}152 \text { men } \\
60 \text { women }\end{array}$ & $\begin{array}{l}\text { DOXY } 200 \mathrm{mg}(\mathrm{d} \text { I), } \\
100 \mathrm{mg}(\mathrm{d} 2-\mathrm{d} 9) \\
\text { Men: I3/76 cured (I7.1\%) } \\
\text { Women: } 10 / 27(37.0 \%)\end{array}$ & $\begin{array}{l}\text { AZM I g stat } \\
\text { Men: } 33 / 39 \text { cured }(84.6 \%) \\
\text { Women: I5/I } 7 \text { cured } \\
(88.2 \%)\end{array}$ \\
\hline $\begin{array}{l}\text { Mena } \\
\text { et } \mathrm{a}^{21}\end{array}$ & 2009 & $\begin{array}{l}\text { Randomized } \\
\text { controlled trial }\end{array}$ & $\begin{array}{l}398 \text { men with NGU } \\
\text { attending an STI clinic, USA }\end{array}$ & 78 men & $\begin{array}{l}\text { DOXY } 100 \text { mg I } 2 \text { hourly } \times 7 d \\
\text { |4/3 | cured }(45.2 \%)\end{array}$ & $\begin{array}{l}\text { AZM I g stat } \\
20 / 23 \text { cured }(87.0 \%)\end{array}$ \\
\hline $\begin{array}{l}\text { Schwebke } \\
\text { et } \mathrm{al}^{22}\end{array}$ & 2011 & $\begin{array}{l}\text { Randomized } \\
\text { controlled trial }\end{array}$ & $\begin{array}{l}305 \text { men with NGU } \\
\text { attending } 4 \text { STI clinics, USA }\end{array}$ & 94 men & $\begin{array}{l}\text { DOXY } 100 \mathrm{mg} I 2 \text { hourly } \times 7 \mathrm{~d} \\
( \pm \text { tinidazole } 2 \mathrm{~g} \text { stat }) \\
12 / 39 \text { cured }(30.8 \%)\end{array}$ & $\begin{array}{l}\text { AZM I g stat } \\
\text { ( } \pm \text { tinidazole } 2 \text { g stat) } \\
30 / 45 \text { cured }(66.7 \%)\end{array}$ \\
\hline $\begin{array}{l}\text { Manhart } \\
\text { et } \mathrm{al}^{23}\end{array}$ & 2013 & $\begin{array}{l}\text { Randomized } \\
\text { controlled trial }\end{array}$ & $\begin{array}{l}606 \text { men with NGU } \\
\text { attending an STI clinic, USA }\end{array}$ & 80 men & $\begin{array}{l}\text { DOXY } 100 \text { mg } 12 \text { hourly } \times 7 \text { d } \\
(+ \text { AZM placebo) } \\
8 / 27 \text { cured }(29.6 \%, \text { mITT })\end{array}$ & $\begin{array}{l}\text { AZM I g stat } \\
\text { (+ DOXY placebo) } \\
\text { I5/38 cured }(39.5 \%, \mathrm{mITT})\end{array}$ \\
\hline
\end{tabular}

Abbreviations: M. genitalium, Mycoplasma genitalium; NGU, non-gonococcal urethritis; STI, sexually transmitted infection; DOXY, doxycycline; TET, tetracycline; LYME, lymecycline; AZM, azithromycin; d, day/days; mITT, modified intention to treat population.

as above. The extended $1.5 \mathrm{~g}$ regimen had previously been reported to be very effective as a first-line treatment for M. genitalium infection. ${ }^{17}$ This extended regimen was generally not used to treat individuals at their first clinic visit but rather reserved to treat individuals with a laboratoryconfirmed diagnosis of $M$. genitalium infection or sexual contacts of individuals with recently diagnosed $M$. genitalium urethritis or cervicitis. Single-dose azithromycin $1 \mathrm{~g}$ was significantly more effective than doxycycline, curing $85 \%$ versus $17 \%$ of men, and $88 \%$ versus $37 \%$ of women. This study did not directly compare the efficacy of the single $1 \mathrm{~g}$ dose and the extended $1.5 \mathrm{~g}$ regimen of azithromycin, but reported that the extended azithromycin regimen, given after doxycycline had failed, was more effective in eradicating M. genitalium (45/47, 96\%) compared with an initial single $1 \mathrm{~g}$ dose $(33 / 39,85 \%) .{ }^{20}$ Although this difference was not statistically significant $(P=0.133)$, the findings have substantially influenced clinical practice.

In contrast, a retrospective Norwegian study reported no difference in efficacy of three different azithromycin regimens: $1 \mathrm{~g}$ stat, $1 \mathrm{~g}$ on day 1 and a repeated $1 \mathrm{~g}$ dose on days 5-7, or the extended $1.5 \mathrm{~g}$ regimen. ${ }^{24}$ Azithromycin efficacy was lower in this retrospective Norwegian study (72\%-79\%) compared with the non-randomized controlled trial in Swedish and Norwegian clinics. The authors postulated that routine use of azithromycin $1 \mathrm{~g}$ in Norway may select for azithromycin-resistant M. genitalium strains..$^{20,24}$ Additionally, the extended $1.5 \mathrm{~g}$ regimen of azithromycin was found to be ineffective once azithromycin $1 \mathrm{~g}$ singledose treatment had failed. ${ }^{24}$

The first randomized clinical trial of $M$. genitalium treatment compared azithromycin $1 \mathrm{~g}$ with doxycycline $100 \mathrm{mg}$ twice daily for 7 days, and confirmed the results of previous non-randomized trials and observational studies, ie, that a single $1 \mathrm{~g}$ dose of azithromycin was more effective than doxycycline for treatment of $M$. genitalium infection in the USA at the time of the study (2002-2004). ${ }^{21}$ However, before the results of this trial were published, a higher rate of azithromycin $1 \mathrm{~g}$ treatment failure was reported among M. genitalium-infected patients in Australia. ${ }^{28}$ In this report, macrolide resistance was identified in strains from patients failing azithromycin treatment. The authors also 


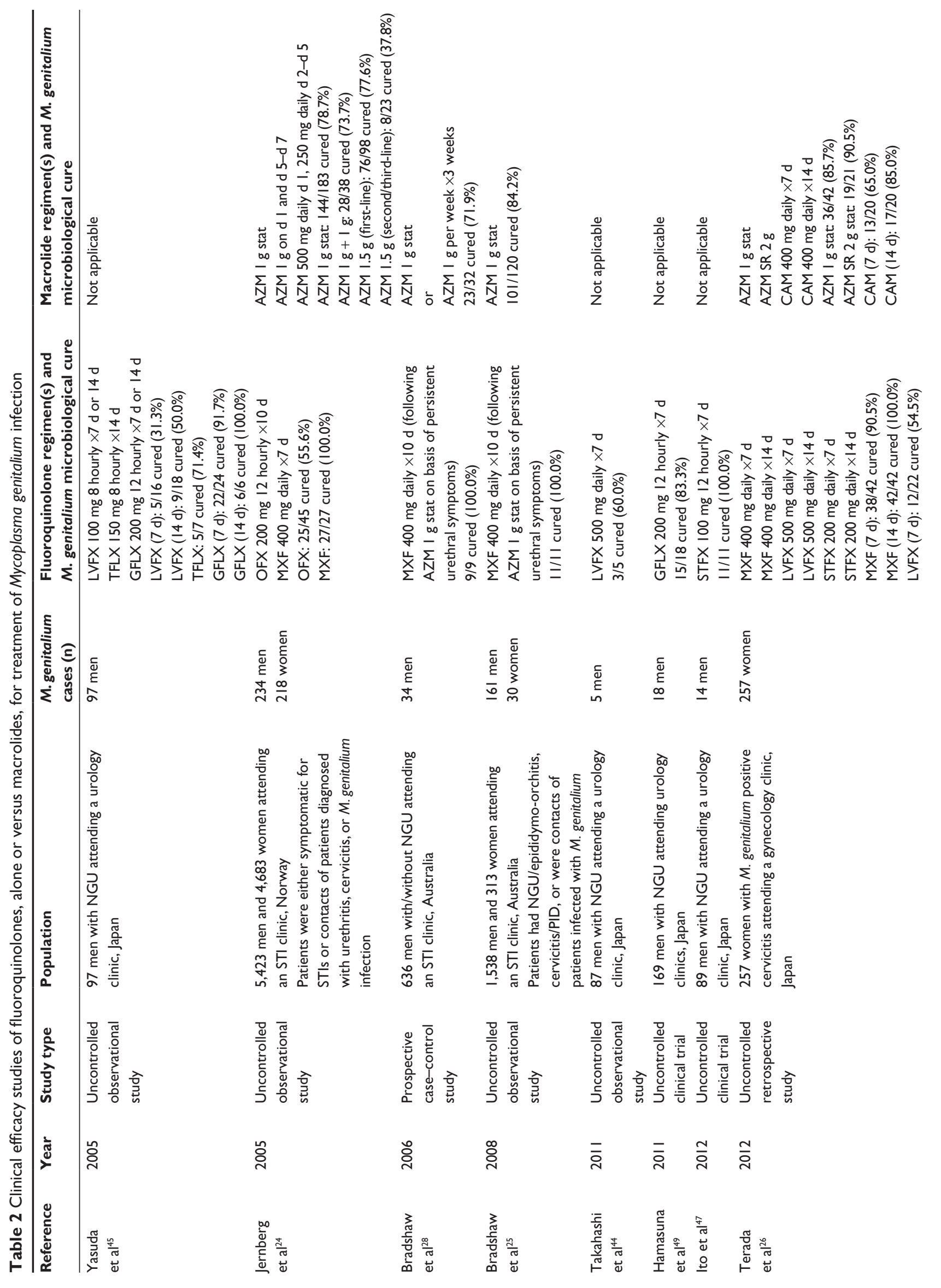




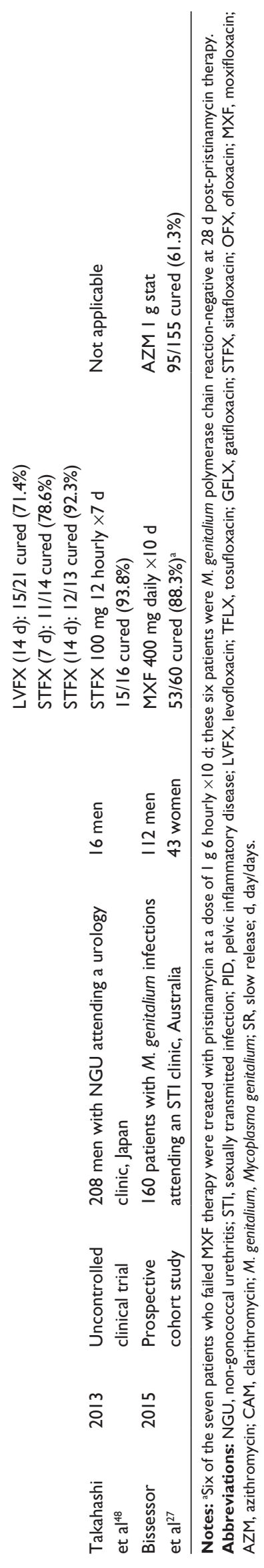

reported that moxifloxacin eradicated all cases of persistent infection. ${ }^{28}$

By 2009, experts had become concerned about the suboptimal effectiveness of the azithromycin $1 \mathrm{~g}$ single-dose regimen, given the premise that treatment should cure at least $95 \%$ of uncomplicated STIs. ${ }^{29}$ The comparative efficacy of the extended $1.5 \mathrm{~g}$ azithromycin regimen has never been assessed in a randomized controlled trial and, unfortunately, it was not included in the design of two large NGU treatment trials that were taking place in the USA at the same time..$^{22,23}$

Anagrius et al have shed further light onto the question of choice of azithromycin regimen. ${ }^{30}$ Consistent with previous observational clinical studies, they did not find a significant difference in treatment efficacy between the single $1 \mathrm{~g}$ and extended $1.5 \mathrm{~g}$ doses. However, seven patients who had macrolide-susceptible $M$. genitalium infection prior to treatment with azithromycin $1 \mathrm{~g}$, and who failed initial treatment, had emergent macrolide resistance. In contrast, the single man who failed the extended $1.5 \mathrm{~g}$ course of azithromycin was infected with a macrolide-resistant strain of M. genitalium, and 77/77 individuals without pre-existing macrolide resistance were cured by this regimen as either first-line or second-line treatment. ${ }^{30}$

A strong and consistent association between presence of 23S rRNA gene mutations and failure of azithromycin treatment began to emerge when clinical outcomes and M. genitalium resistance testing results were correlated (Table 3). ${ }^{7,31,32}$ However, it should be noted that epidemiological studies have the potential to overestimate population prevalence of resistance when clinical information about previous antibiotic treatment is unavailable. ${ }^{33}$ In addition, patients with macrolide resistance mutations may still test negative after treatment with single-dose azithromycin. ${ }^{34} \mathrm{This}$ outcome may reflect failure to detect persistent infection due to low bacterial loads associated with $M$. genitalium infection or to natural resolution of infection. ${ }^{31,35,36}$

An alarming trend is now apparent, with macrolideresistant $M$. genitalium being widely reported as the underlying cause for the increasing rates of treatment failure with the azithromycin $1 \mathrm{~g}$ single-dose regimen. Although suboptimal macrolide dosage appears to be the main driver of the observed trend, the role of socioepidemiological factors, for example importation of antimicrobial-resistant $M$. genitalium strains or transmission of these within defined sexual networks, remains uncertain and requires more research. ${ }^{28,31,37}$

The presence of macrolide resistance-associated mutations has been highly associated with failure to eradicate M. genitalium in several Australian clinical studies. ${ }^{28,31,36}$ 


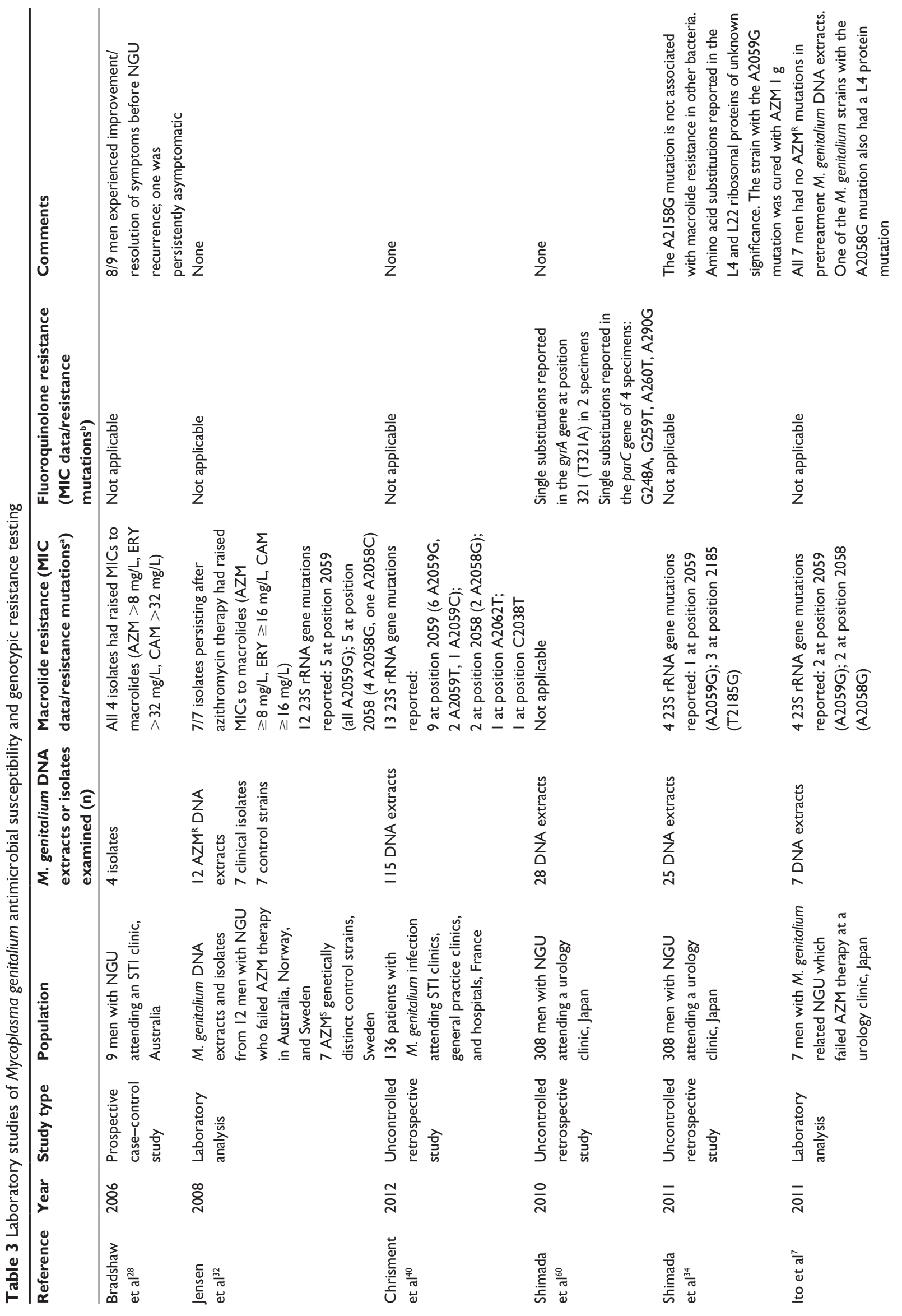



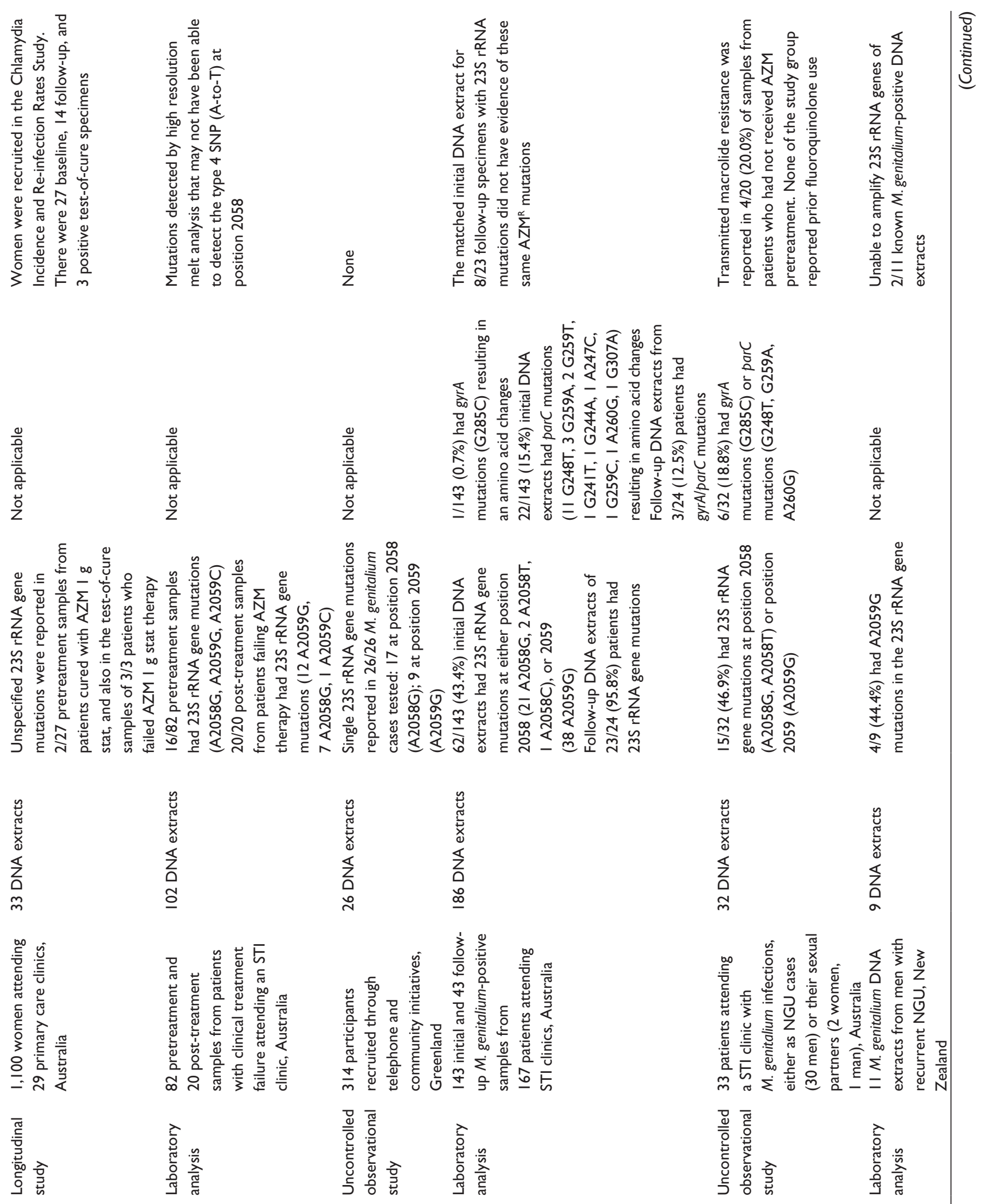

高京

⿳亠口冋

⿳亠丷⿵冂丶

$\bar{i}$

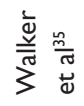

$\frac{\bar{m}}{\sqrt{c}}$
$\frac{0}{5}$
$\stackrel{\frac{5}{3}}{r}$

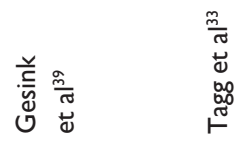

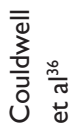

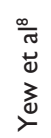




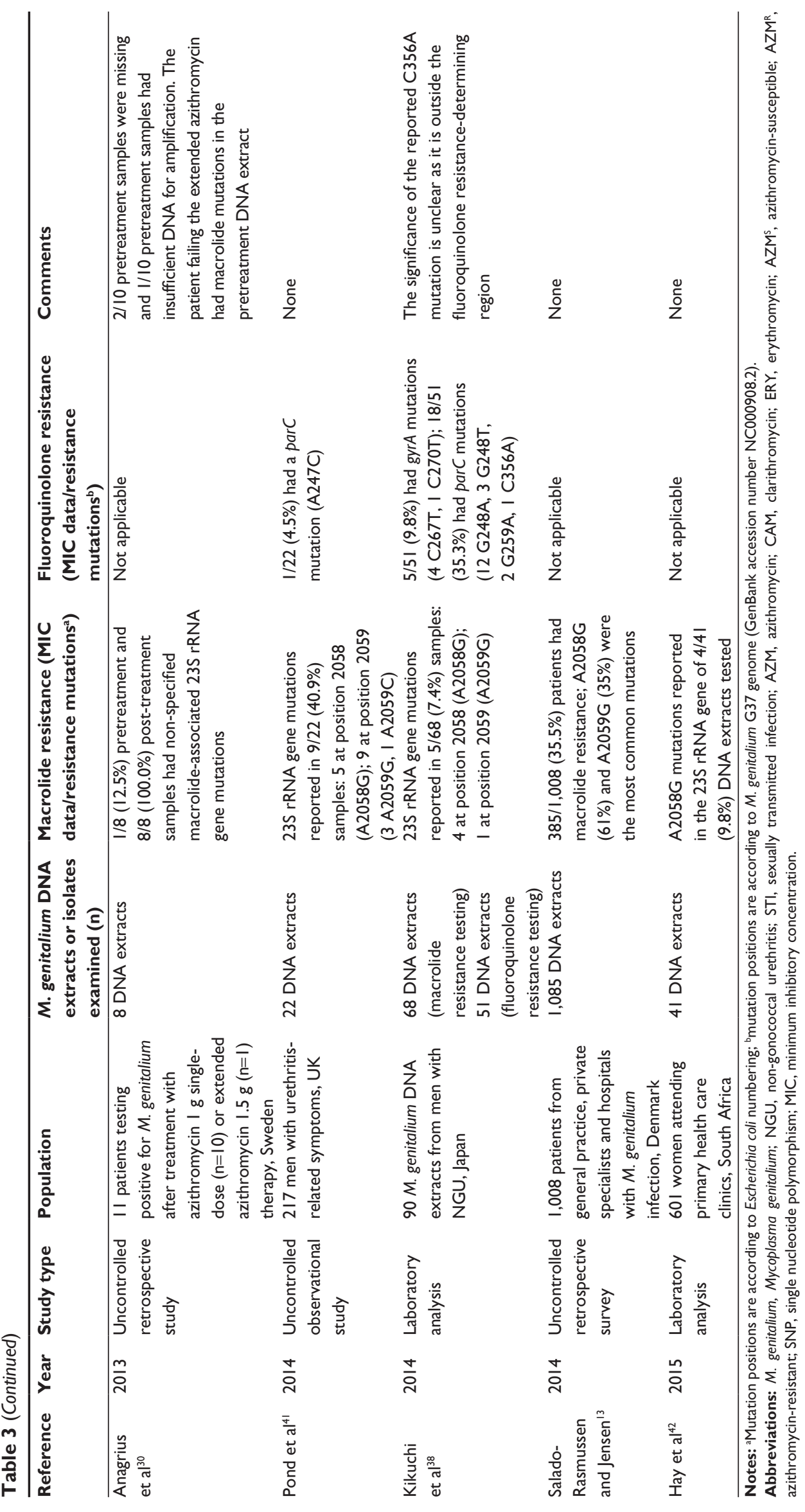


In Melbourne, Australia, azithromycin efficacy has declined from $84 \%$ between 2005 and 2007, and to 69\% from 2007 to $2009(P<0.001) .{ }^{31}$ Elsewhere in the Pacific region, macrolide resistance mutations were not detected in a small number of M. genitalium-positive urethral samples from Japanese men tested in 2011-2012, whereas five (29.4\%) of 17 screened M. genitalium DNA extracts had 23S rRNA gene mutations in 2013. ${ }^{38} \mathrm{~A}$ similar trend has been observed in the USA where, by 2011 , only $40 \%$ of infections were cured by single-dose azithromycin $1 \mathrm{~g}$, compared with $87 \%$ in 2002-2004. ${ }^{21,23}$

In Scandinavia, a retrospective case study in Sweden tracked the trajectory of macrolide resistance from 2006 to 2007, when no macrolide resistance was detected, through to 2011 , when $21 \%$ of $M$. genitalium-positive samples harbored 23S rRNA gene mutations associated with macrolide resistance. ${ }^{30} \mathrm{~A}$ Danish national survey reported a $38 \%$ prevalence of macrolide resistance-associated mutations in first M. genitalium test samples from 2007 to $2010 .{ }^{13}$ The lowest rate of resistance was found in samples from private specialists, mostly gynecologists who were conducting screening for STIs including $M$. genitalium. The highest rate occurred among STI clinic patients where $M$. genitalium testing was generally restricted to persistently symptomatic patients with negative results for other pathogens; these patients were likely to have received azithromycin treatment prior to their first $M$. genitalium test. In an alarming report from Greenland, $100 \%$ of M. genitalium strains detected in 2008-2009 carried macrolide resistance mutations, resulting in replacement of azithromycin with tetracyclines in the recommended syndromic treatment guideline for urethritis and cervicitis. ${ }^{39}$

Elsewhere in Europe, the rate of macrolide resistance varied in France from 10\% to $15 \%$ each year from 2006 to 2010, whereas no resistance mutations were detected in the small number of available samples from 2003 to $2005 .{ }^{40}$ There was, however, no significant trend observed between 2003 and 2006 or between 2007 and 2010. In the UK, $M$. genitalium was detected in five asymptomatic and 17 symptomatic men with and without urethritis in a London clinic. ${ }^{41}$ Among these 22 initial samples, nine harbored macrolide-associated resistance mutations, and phylogenetic analysis of 18 samples revealed two main clusters within which strain types were not closely related. None of the men with urethritis and with macrolide-resistant strains of M. genitalium returned for follow-up, despite having received treatment with either doxycycline or azithromycin $1 \mathrm{~g}$ that would have been unlikely to cure their infections.

There is a lack of data on the prevalence of macrolide resistance-associated mutations among the $M$. genitalium strains circulating in African, Asian, and Latin American countries. Many countries within these continental regions rely on syndromic management for STI control, and laboratory diagnostic capability is generally absent or very minimal. In addition, tetracyclines are preferred to macrolides for syndromic management of genital discharges due to the differential cost and limited budget for STI control. Accordingly, it remains very unclear as to what role $M$. genitalium plays in reproductive tract morbidity in resource-poor settings and to what extent $M$. genitalium strains have acquired resistance mutations. The only reported macrolide resistance data from Africa has been laboratorybased using remnant specimens collected over 4 months in 2011-2012 in a limited geographic area in rural South Africa. ${ }^{42}$ The authors reported a prevalence of $23 \mathrm{~S}$ rRNA gene mutations in four $(9.8 \%)$ of 41 DNA extracts screened. We were unable to find any studies reporting macrolideassociated mutations in $M$. genitalium strains from Latin America or resource-poor countries in Asia.

The most recent data on macrolide resistance is from a prospective cohort of M. genitalium-infected patients with NGU, cervicitis, or pelvic inflammatory disease, as well as their sexual contacts, enrolled in Melbourne, Australia, between June 2012 and July $2013 .{ }^{27}$ Only 3\% of patients were lost to follow-up; 95 (61\%) of 155 were microbiologically cured by single-dose azithromycin $1 \mathrm{~g}$. Baseline macrolide resistance was detected in $56(36 \%)$ patients (transmitted resistance) and most $(87 \%)$ of these failed azithromycin therapy. In addition, eleven $(11 \%)$ of the 99 patients without baseline macrolide resistance also developed signature $23 \mathrm{~S}$ rRNA gene mutations (induced resistance) and failed therapy. Overall, a high azithromycin $1 \mathrm{~g}$ treatment failure rate $(39 \%)$ was reported in this study. ${ }^{27}$ This study provided the first definitive evidence for timing of test of cure; all patients who tested negative for M. genitalium at day 28 by polymerase chain reaction (PCR) assay also tested negative by day 14 .

Fluoroquinolones such as moxifloxacin, gatifloxacin, and sitafloxacin remain highly active against most macrolideresistant $M$. genitalium isolates. ${ }^{43}$ Although demonstrated to have high activity against $M$. genitalium in vitro, the newer fluoroquinolones, including gemifloxacin, sparfloxacin, grepafloxacin, trovafloxacin, and garenoxacin, have yet to be evaluated in clinical trials. ${ }^{43}$ In contrast, ciprofloxacin has poor activity, and both ofloxacin and levofloxacin are less active against $M$. genitalium than moxifloxacin and the newer fluoroquinolones mentioned above.

Ofloxacin and levofloxacin have been used to treat NGU in the past, particularly in Japan, although neither are ideal 
drugs to treat $M$. genitalium infection. ${ }^{43,44}$ Levofloxacin, given as $100 \mathrm{mg}$ 8-hourly for 7 days or 14 days has been shown to produce low M. genitalium eradication rate of $31 \%$ or $50 \%$, respectively, and has been associated with a high prevalence of recurrence of urethral discharge. ${ }^{45,46}$ In a small study with nine evaluable patients, a 10-day course of ofloxacin $200 \mathrm{mg}$ 12 hourly failed to clear M. genitalium in $56 \%$ of cases. ${ }^{24}$

Moxifloxacin $400 \mathrm{mg}$ once daily for 7-10 days generally cures $M$. genitalium infections that have failed azithromycin therapy. ${ }^{25,32}$ As a result, moxifloxacin is currently the treatment of choice for macrolide-resistant $M$. genitalium infections. Based on the results of in vitro susceptibility testing, sitafloxacin appears to be as active as moxifloxacin. Two recent small clinical studies in Japan, where moxifloxacin is not available, reported that a $100 \mathrm{mg}$ 12-hourly regimen of sitafloxacin for 1 week eradicated $M$. genitalium in $11 / 11$ and $15 / 16$ patients, respectively, including five patients with persistent or recurrent NGU. ${ }^{47,48}$ Although no longer available, gatifloxacin, given at a dosage of $200 \mathrm{mg}$ 12-hourly for 1 or 2 weeks, also resulted in high eradication rates for $M$. genitalium in men with NGU. ${ }^{45,49}$

The first clinical report of moxifloxacin treatment failure associated with fluoroquinolone-associated resistance mutations in M. genitalium strains emerged in 2013 from Sydney, Australia. ${ }^{36}$ A recent study from Melbourne found that moxifloxacin cured only 53 (88\%) of 60 macrolide-resistant M. genitalium infections; the seven that failed moxifloxacin had fluoroquinolone-associated resistance mutations in gyr $A$ and parC. ${ }^{27}$ Accordingly, it is strongly recommended that clinicians avoid low-efficacy fluoroquinolones, such as levofloxacin or ofloxacin, to treat NGU cases for fear of driving a rise in the prevalence of fluoroquinolone resistance among $M$. genitalium strains. While most $M$. genitalium strains remain susceptible to moxifloxacin and sitafloxacin, there is increasing concern about how best to treat dual macrolide-resistant and fluoroquinolone-resistant $M$. genitalium infections.

A new fluoroketolide antibiotic, solithromycin, has shown superior in vitro activity against $M$. genitalium compared with macrolides, fluoroquinolones, and tetracyclines. ${ }^{50}$ When tested against macrolide-resistant strains, solithromycin was more active in vitro than azithromycin, although there was evidence of some cross-resistance. ${ }^{50}$ Mutations in the M. genitalium 23S rRNA gene at position 2058 (Escherichia coli numbering) led to higher solithromycin minimum inhibitory concentrations (MICs) than those in position 2059 and were the only changes explaining solithromycin resistance. In Denmark, where $40 \%$ of $M$. genitalium strains are azithromycin-resistant, the authors postulate that $85 \%$ of these resistant strains, or $94 \%$ of all $M$. genitalium strains, would be susceptible to solithromycin. Superior activity is thought to be due to solithromycin having three ribosomal binding sites, compared with only one in the case of azithromycin. Solithromycin also showed good activity against five strains from patients who had failed both azithromycin and moxifloxacin treatment. ${ }^{50}$ This antimicrobial agent was recently shown to be highly effective against $C$. trachomatis and $N$. gonorrhoeae in vitro and against uncomplicated urogenital gonorrhea in a Phase II clinical trial, suggesting it could treat several STIs simultaneously. ${ }^{51-53}$ Should the efficacy of solithromycin be demonstrated in further clinical trials, it may be an option for the syndromic management of urethritis and related clinical syndromes in the future.

Pristinamycin, a streptogramin antimicrobial generally used to treat vancomycin-resistant Enterococcus faecium bacteremia and complicated skin infections caused by methicillin-resistant Staphylococcus aureus, has also been used to treat $M$. genitalium infections. Bissessor et al administered pristinamycin in a regimen of $1 \mathrm{~g} 6$ hourly for 10 days to six patients who failed both azithromycin ( $1 \mathrm{~g}$ as a single dose) and moxifloxacin (400 mg daily for 10 days). ${ }^{27}$ All six patients remained PCR-negative for $M$. genitalium 28 days after receiving the pristinamycin. As this study represents the first reported use of pristinamycin among a small group of patients infected with multi-drug resistant $M$. genitalium, further clinical evaluations are required in order to better evaluate the effectiveness, optimal dosage, and potential for acquisition of antimicrobial resistance determinants. Even if pristinamycin continues to prove effective, its currently limited availability and high cost do not support wider use, particularly in resource-poor settings.

\section{Antimicrobial resistance testing in M. genitalium}

M. genitalium was first cultured by direct inoculation of urethral swab material onto SP4 Mycoplasma medium and subsequently by coculture of urethral specimens with Vero cell cultures grown in supplemented serum-free medium. ${ }^{54,55}$ M. genitalium has now been successfully isolated from urethral swabs, urinary sediments, and cervical swabs. ${ }^{56}$ In vitro antimicrobial susceptibility testing traditionally requires isolation of a single strain through multiple passages in culture (axenic culture). This has proven difficult due to the fastidious nutritional and environmental requirements of M. genitalium as well as its slow growth; indeed, it can take up to 6 months to isolate a single colony. This propensity of $M$. genitalium culture to fail has impeded studies reliant 
on observations of bacterial growth following addition of serial dilutions of antimicrobial agents to SP4 medium-based axenic cultures. ${ }^{56}$

In an attempt to overcome the challenges of strain loss with subsequent subcultures, the growth of $M$. genitalium in inoculated Vero cell cultures has been monitored by use of a quantitative TaqMan $5^{\prime}$ nuclease real-time PCR, which in turn relies on detection of the single-copy $m g p B$ adhesion gene. ${ }^{57}$ In this assay, growth inhibition due to the presence of antimicrobial agents can be expressed as a proportion of the DNA load of $M$. genitalium controls grown in the same culture system. Whichever method is used, phenotypic resistance testing for $M$. genitalium remains a laborious and time-consuming process. Consequently, there are relatively few antimicrobial susceptibility studies reported in the literature. The data that do exist may not be representative of the larger number of untested $M$. genitalium strains circulating on a global level.

Advances in techniques to detect putative resistance mutations in initial culture specimens without the need for axenic culture, and more recently, directly from clinical samples, have facilitated epidemiological studies of $M$. genitalium resistance, as well as correlation of clinical outcomes with results of genotypic resistance testing. ${ }^{31,33,56,58}$ Rapid high resolution melt analysis (HRMA) now allows detection of macrolide resistance-associated mutations at the time of initial detection of $M$. genitalium. This dramatically reduces the time needed to perform resistance testing, which may be as long as 2-3 months for previously described in vitro MIC determination based on the Vero cell culture system and quantitative TaqMan $5^{\prime}$ nuclease realtime PCR determination of growth inhibition. ${ }^{32,57}$ However, the rapid HRMA assay was unable to detect type IV single nucleotide polymorphisms within the $23 \mathrm{~S}$ rRNA gene at position 2058 (ie, A2058T, E. coli numbering). ${ }^{31}$ This is an important limitation of the HRMA assay as A2058T mutations do comprise a small proportion of macrolide resistance-associated mutations in some reports. ${ }^{13,33,38}$ A real-time PCR assay based on fluorescence resonance energy transfer coupled with melting curve analysis was reported to be more discriminatory and reproducible in clinical specimens when compared with the rapid HRMA assay ${ }^{58}$ Use of such rapid assays on specimens collected prior to treatment avoids the wait for a test-of-cure result before instituting second-line treatment for patients with persistent NGU. However, treatment would not be expedited for those azithromycin-treated men who developed emergent macrolide resistance following therapy.

\section{Overview of mutations associated with resistance and treatment failure Tetracyclines}

In vitro antimicrobial susceptibility testing of recent clinical isolates has demonstrated the emergence of some strains with decreased susceptibility to doxycycline $(1 \mu \mathrm{g} / \mathrm{mL})$ and tetracycline $(4 \mu \mathrm{g} / \mathrm{mL}) .{ }^{16}$ Although tetracycline resistanceassociated mutations have not so far been identified in $M$. genitalium, tet $M$ gene mutations conferring tetracycline resistance have been identified in M. hominis and Ureaplasma urealyticum isolated from genital specimens. ${ }^{43}$

\section{Macrolides}

Macrolide antibiotics, including azithromycin, prevent bacterial replication by binding to the $50 \mathrm{~S}$ ribosomal subunit, inhibiting translation of mRNA and thus interfering with protein synthesis. Mutations at positions 2058 and 2059 (E. coli numbering) in region $\mathrm{V}$ of the $23 \mathrm{~S}$ rRNA gene alter ribosomal structure, thereby preventing macrolide binding, and have been associated with macrolide resistance in a number of pathogenic bacteria, including $M$. genitalium and two other sexually acquired pathogens, $N$. gonorrhoeae and Treponema pallidum. ${ }^{59}$ While the latter two sexually transmitted pathogens have multiple copies of 23S rRNA genes, $M$. genitalium has only a single rRNA gene operon encoding for the $23 \mathrm{~S}, 16 \mathrm{~S}$, and $5 \mathrm{~S}$ rRNA subunits. It has been hypothesized that this relative deficiency in the number of $23 \mathrm{~S}$ rRNA gene copies may increase the susceptibility of $M$. genitalium to develop high-level macrolide resistance. ${ }^{38}$ In addition, the ability of $M$. genitalium to exist intracellularly, together with its very slow growth, could favor selection of macrolide-resistant strains, given that azithromycin has a much longer intracellular than extracellular half-life. ${ }^{3}$

The first study to demonstrate macrolide resistance in azithromycin treatment failure in $M$. genitalium urethritis was reported in $2006 .{ }^{28}$ The authors performed phenotypic antimicrobial drug susceptibility testing on four specimens, collected after azithromycin $1 \mathrm{~g}$ single-dose treatment had failed, and reported increased MICs to azithromycin ( $>8 \mathrm{mg} / \mathrm{L})$, erythromycin (>32 mg/L), and clarithromycin (>32 mg/L). All four isolates were sensitive to moxifloxacin, with MICs in the range of $0.031-0.125 \mathrm{mg} / \mathrm{L}$, and retained in vitro susceptibility to doxycycline (MICs $0.125-0.25 \mathrm{mg} / \mathrm{L}$ ). ${ }^{28}$

In an attempt to determine the genetic mechanism underlying the observed macrolide resistance, these four isolates and three macrolide-resistant $M$. genitalium isolates from 
Scandinavian patients, who had also failed azithromycin, were further studied along with several distinct azithromycinsusceptible $M$. genitalium strains. ${ }^{32}$ The genetic basis for drug resistance was determined by sequencing the $23 \mathrm{~S}$ rRNA gene, as well as genes encoding L4 and L22 proteins, as mutations with these genes were already associated with macrolide resistance in other Mollicutes.

The authors identified three different mutations at positions 2058 and 2059 (E. coli numbering) in region $\mathrm{V}$ of the $23 \mathrm{~S}$ rRNA gene which were deemed responsible for the macrolide resistance phenotype. ${ }^{32}$ Although some point mutations were found in the L4 and L22 genes, most of them did not result in amino acid changes, and their effect was thought to be minor or non-existent in terms of the expression of the macrolide-resistant phenotype. Only one strain possessed an amino acid substitution, ie, the H69R mutation in L4, known to be associated with macrolide resistance in Mollicutes. The authors subsequently developed and validated a PCR assay to detect macrolide resistance-associated mutations. ${ }^{32}$ Nine paired pretreatment and post-treatment samples from patients who failed a single dose $1 \mathrm{~g}$ dose of azithromycin were further analyzed with this assay. Macrolide resistance-associated 23S rRNA gene mutations were present in two of the pretreatment DNA extracts and all of the nine post-treatment DNA extracts, suggesting that azithromycin resistance had emerged during treatment. Induced macrolide resistance has subsequently been reported by others. ${ }^{7,8}$

Researchers in Melbourne, Australia, reported that rapid HRMA detected sexually transmitted macrolide resistance mutations in $16(20 \%)$ of 82 pretreatment samples, while selection of macrolide resistance-associated mutations occurred in eleven (55\%) of 20 of those with initial wildtype infections who failed initial treatment. ${ }^{31}$ Elsewhere in Australia, macrolide resistance-associated mutations were detected by sequencing of PCR amplicons in 62 (43\%) of 143 initial $M$. genitalium-positive samples collected in Sydney from 2008 to $2011 .{ }^{33}$ Sexually transmitted macrolide resistance was present in four $(20 \%)$ of a small subset of 20 samples collected from patients who had never received azithromycin prior to their first test. ${ }^{36}$

\section{Fluoroquinolones}

Fluoroquinolone antibiotics bind to the DNA gyrase and topoisomerase IV enzymes, blocking DNA replication. Mutations in defined regions of the DNA gyrase genes, gyr $A$ and $g y r B$, and the topoisomerase IV genes, parC and parE, have been linked to high-level fluoroquinolone resistance in various bacteria, including $N$. gonorrhoeae and M. genitalium..$^{5,33}$

As mentioned above, the first clinical reports of M. genitalium infection failing therapy with moxifloxacin as a result of fluoroquinolone-associated resistance mutations emerged in $2013 .{ }^{36}$ Fluoroquinolone resistance-associated mutations in the $\mathrm{parC}$ and/or gyrA genes were detected in eleven (15\%) of 143 initial $M$. genitalium PCR-positive samples from Sydney and in six (19\%) of 32 of these samples from patients at one clinic. ${ }^{33,36}$ In this population, fluoroquinolone antibiotics are not used for treatment of any STIs or widely in the community for the treatment of other infectious diseases. Despite this, fluoroquinolone resistance-associated mutations were significantly associated with failure of moxifloxacin treatment $(P=0.005) .{ }^{36}$ Patients infected with $M$. genitalium strains containing both macrolide and fluoroquinolone resistance-associated mutations failed therapy with both azithromycin and moxifloxacin, raising concerns about untreatable $M$. genitalium infection in the future.

Subsequently, fluoroquinolone resistance was also reported from a London clinic. ${ }^{41}$ In addition, approximately one-third of 51 Japanese men with NGU were infected with M. genitalium and had fluoroquinolone resistance-associated mutations in parC, but 9/9 were cured by sitafloxacin $100 \mathrm{mg}$ prescribed twice daily for 7 days. ${ }^{38}$ The relatively high prevalence of fluoroquinolone resistance in this patient group may be a consequence of the common use of fluoroquinolones in STI treatment in Japan. ${ }^{60}$

\section{Future directions}

Despite mounting evidence of increasing failure of azithromycin $1 \mathrm{~g}$ as a single-dose treatment for M. genitaliumassociated $\mathrm{NGU}$, this regimen continues to be used as first-line treatment for NGU in many parts of the world. This is in part because NGU treatment remains focused on treating chlamydial infections, which are deemed to have more serious sequelae. While $C$. trachomatis is universally accepted as an STI, the pathogen status of $M$. genitalium is not so prominent, which has in turn led to recent calls for M. genitalium to be regarded more seriously and to be recognized as a significant STI with associated morbidity. ${ }^{2,10}$ Once this happens, there will be enhanced efforts to introduce commercial assays for $M$. genitalium detection, ideally multiplexed with $C$. trachomatis and $N$. gonorrhoeae. In resource-poor settings, more effort is required to validate genital discharge syndromic management protocols that could adequately treat both $C$. trachomatis and M. genitalium infections. 
STI treatments are devised according to the local epidemiology of antimicrobial susceptibility, but generating such data for $M$. genitalium strains would be a major and ongoing challenge for laboratories. Diagnostic testing for $M$. genitalium has not been widely available, and antimicrobial susceptibility testing remains available in only a few laboratories worldwide. ${ }^{9}$ Consequently, the issue of macrolide treatment failure in $M$. genitalium infection was unrecognized until relatively recently. It is clear, in retrospect, that the choice of treatment for $M$. genitalium infections within the context of NGU has always been inadequate. By the time that randomized trials were designed to investigate $M$. genitalium treatment, macrolide resistance among $M$. genitalium strains was entrenched and rising. Evidence of increasing failure of azithromycin in the treatment of NGU re-emphasizes the ease with which antibiotic resistance can accelerate where suboptimal treatment is provided for a common infection or syndrome.

There are now calls to abandon single-dose azithromycin $1 \mathrm{~g}$ treatment for $M$. genitalium and related clinical syndromes. ${ }^{10}$ One suggested strategy is to revert to use of doxycycline for treatment of NGU, and to then use the extended regimen of azithromycin $1.5 \mathrm{~g}$ for those who fail initial therapy, with a 10-day course of moxifloxacin as thirdline therapy, and to treat contacts with the same regimen(s). ${ }^{10}$ This approach could be used in settings with or without availability of $M$. genitalium testing, and would potentially slow the rate of resistance development. Its success relies on three premises: firstly, that the extended $1.5 \mathrm{~g}$ azithromycin regimen is sufficiently effective, for which there is limited evidence to date; secondly, that patients who fail therapy will continue to return for follow-up, and lastly that macrolide resistance is not already present. ${ }^{24,30}$ Epidemiological studies have detected circulating macrolide resistance in up to $100 \%$ of local strains in some populations. ${ }^{39}$ In addition, there may be consequences for treatment of other pathogens. For example, suboptimal adherence to doxycycline occurred in $28 \%$ of men in a prospective randomized controlled trial of NGU treatment, and was associated with 9-fold higher risk of microbiological failure among men infected with $C$. trachomatis. ${ }^{61}$

The current practices of performing $M$. genitalium testing primarily in men with NGU and failure to provide systematic screening recommendations for asymptomatic individuals contribute to the selection pressure generating macrolide resistance, especially among groups with high rates of partner change. Given published prevalence data, it is likely that many MSM who receive the single-dose azithromycin
$1 \mathrm{~g}$ treatment, either for chlamydial infection or as dual therapy with ceftriaxone for treatment of gonorrhea, are also asymptomatically infected with rectal $M$. genitalium. ${ }^{15}$ Some infections may be cured, but macrolide resistance probably emerges with high frequency in this scenario, leading to pathogen persistence and onward transmission to sexual partners. In the case of $M$. genitalium infection in women, more than one-third of a cohort of African female sex workers received syndromic treatment for other STIs during follow-up, without any effect on clearance of $M$. genitalium, even though some of these infections would have been expected to respond to fluoroquinolones and doxycycline given as syndromic management for vaginal discharge and lower abdominal pain syndromes. ${ }^{11}$ This finding has led to speculation of widespread $M$. genitalium antimicrobial resistance in sub-Saharan Africa, where in some cohorts and particularly among HIV-infected patients, the prevalence of $M$. genitalium infection exceeds that of gonorrhea and chlamydial infection. ${ }^{62,63}$

Antimicrobial susceptibility surveillance should be instituted more widely, particularly in resource-limited settings where data are either very few or non-existent, to inform treatment guidelines. New molecular technologies have shortened the many months formerly required for antimicrobial susceptibility testing through use of axenic culture systems. It is now possible to test patients' specimens directly for the presence of signature resistance mutations for macrolide and fluoroquinolone resistance..$^{31,57,58}$ Ideally, future $M$. genitalium detection assays would incorporate detection of macrolide resistance mutations, which could improve treatment effectiveness and help limit the spread of resistance. ${ }^{9,13}$

\section{Conclusion}

In conclusion, the minimalist nature of $M$. genitalium, encompassing its error-prone genome, parasitic lifestyle, and slow replication, has ironically proved to be its greatest strength, giving this organism the ability to evade detection and readily develop treatment resistance. Effective management of $M$. genitalium infection, within the context of broader STI control, will ideally require a number of new interventions including: the development and validation of a commercial multiplex assay to detect $N$. gonorrhoeae, $C$. trachomatis, and $M$. genitalium incorporating detection of key resistance mutations; systematic screening of high-risk groups, including screening among MSM for rectal infection; establishment of local and regional surveillance networks to monitor prevalence of infection and antimicrobial resistance; and development and clinical evaluation of new treatments. 
Solithromycin is a promising option, offering a higher barrier to resistance and potential efficacy in syndromic STI treatment in $M$. genitalium-associated clinical syndromes such as NGU, as well as in resource-limited settings.

\section{Disclosure}

The authors report no conflicts of interest in this work.

\section{References}

1. Taylor-Robinson D, Jensen JS. Mycoplasma genitalium: from Chrysalis to multicolored butterfly. Clin Microbiol Rev. 2011;24(3):498-514.

2. Manhart LE. Mycoplasma genitalium: An emergent sexually transmitted disease? Infect Dis Clin North Am. 2013;27(4):779-792.

3. Razin S, Yogev D, Naot Y. Molecular biology and pathogenicity of mycoplasmas. Microbiol Mol Biol Rev. 1998;62(4):1094-1156.

4. Ison CA. Antimicrobial resistance in sexually transmitted infections in the developed world: implications for rational treatment. Curr Opin Infect Dis. 2012;25(1):73-78.

5. Lewis DA. The gonococcus fights back: is this time a knock out? Sex Transm Infect. 2010;86(6):415-421.

6. Lewis DA. The role of core groups in the emergence and dissemination of antimicrobial-resistant N gonorrhoeae. Sex Transm Infect. Dec 2013;89 Suppl 4:iv47-iv51.

7. Ito S, Shimada Y, Yamaguchi Y, et al. Selection of Mycoplasma genitalium strains harbouring macrolide resistance-associated 23S rRNA mutations by treatment with a single $1 \mathrm{~g}$ dose of azithromycin. Sex Transm Infect. 2011;87(5):412-414.

8. Yew HS, Anderson T, Coughlan E, Werno A. Induced macrolide resistance in Mycoplasma genitalium isolates from patients with recurrent nongonococcal urethritis. J Clin Microbiol. 2011;49(4):1695-1696.

9. Manhart LE. Editorial commentary: diagnostic and resistance testing for Mycoplasma genitalium: what will it take? Clin Infect Dis. 2014;59(1): 31-33.

10. Horner P, Blee K, Adams E. Time to manage Mycoplasma genitalium as an STI: but not with azithromycin $1 \mathrm{~g}$ ! Curr Opin Infect Dis. 2014;27(1): 68-74.

11. Vandepitte J, Weiss HA, Kyakuwa N, et al. Natural history of Mycoplasma genitalium infection in a cohort of female sex workers in Kampala, Uganda. Sex Transm Dis. 2013;40(5):422-427.

12. Bradshaw CS, Tabrizi SN, Read TR, et al. Etiologies of nongonococcal urethritis: bacteria, viruses, and the association with orogenital exposure. J Infect Dis. 2006;193(3):336-345.

13. Salado-Rasmussen K, Jensen JS. Mycoplasma genitalium testing pattern and macrolide resistance: a Danish nationwide retrospective survey. Clin Infect Dis. 2014;59(1):24-30.

14. Bradshaw CS, Fairley CK, Lister NA, Chen SJ, Garland SM, Tabrizi SN. Mycoplasma genitalium in men who have sex with men at male-only saunas. Sex Transm Infect. 2009;85(6):432-435.

15. Soni S, Alexander S, Verlander N, et al. The prevalence of urethral and rectal Mycoplasma genitalium and its associations in men who have sex with men attending a genitourinary medicine clinic. Sex Transm Infect. 2010;86(1):21-24.

16. Hamasuna R, Jensen JS, Osada Y. Antimicrobial susceptibilities of Mycoplasma genitalium strains examined by broth dilution and quantitative PCR. Antimicrob Agents Chemother. 2009;53(11):4938-4939.

17. Falk L, Fredlund H, Jensen JS. Tetracycline treatment does not eradicate Mycoplasma genitalium. Sex Transm Infect. 2003;79(4):318-319.

18. Johannisson G, Enstrom Y, Lowhagen GB, et al. Occurrence and treatment of Mycoplasma genitalium in patients visiting STD clinics in Sweden. Int J STD AIDS. 2000;11(5):324-326.

19. Gambini D, Decleva I, Lupica L, Ghislanzoni M, Cusini M, Alessi E. Mycoplasma genitalium in males with nongonococcal urethritis: prevalence and clinical efficacy of eradication. Sex Transm Dis. 2000; 27(4):226-229.
20. Björnelius E, Anagrius C, Bojs G, et al. Antibiotic treatment of symptomatic Mycoplasma genitalium infection in Scandinavia: a controlled clinical trial. Sex Transm Infect. 2008;84(1):72-76.

21. Mena LA, Mroczkowski TF, Nsuami M, Martin DH. A randomized comparison of azithromycin and doxycycline for the treatment of Mycoplasma genitalium-positive urethritis in men. Clin Infect Dis. 2009;48(12):1649-1654.

22. Schwebke JR, Rompalo A, Taylor S, et al. Re-evaluating the treatment of nongonococcal urethritis: emphasizing emerging pathogens a randomized clinical trial. Clin Infect Dis. 2011;52(2):163-170.

23. Manhart LE, Gillespie CW, Lowens MS, et al. Standard treatment regimens for nongonococcal urethritis have similar but declining cure rates: a randomized controlled trial. Clin Infect Dis. 2013;56(7): 934-942.

24. Jernberg E, Moghaddam A, Moi H. Azithromycin and moxifloxacin for microbiological cure of Mycoplasma genitalium infection: an open study. Int J STD AIDS. 2008;19(10):676-679.

25. Bradshaw CS, Chen MY, Fairley CK. Persistence of Mycoplasma genitalium following azithromycin therapy. PLoS One. 2008;3(11):e3618.

26. Terada M, Izumi K, Ohki E, Yamagishi Y, Mikamo H. Antimicrobial efficacies of several antibiotics against uterine cervicitis caused by Mycoplasma genitalium. J Infect Chemother. 2012;18(3):313-317.

27. Bissessor M, Tabrizi SN, Twin J, et al. Macrolide resistance and azithromycin failure in a Mycoplasma genitalium-infected cohort and response of azithromycin failures to alternative antibiotic regimens. Clin Infect Dis. 2015;60(8):1228-1236.

28. Bradshaw CS, Jensen JS, Tabrizi SN, et al. Azithromycin failure in Mycoplasma genitalium urethritis. Emerg Infect Dis. 2006;12(7): 1149-1152.

29. Jensen JS. Single-dose azithromycin treatment for Mycoplasma genitalium-positive urethritis: best but not good enough. Clin Infect Dis. 2009;48(12):1655-1656.

30. Anagrius C, Lore B, Jensen JS. Treatment of Mycoplasma genitalium. Observations from a Swedish STD clinic. PLoS One. 2013; 8(4):e61481.

31. Twin J, Jensen JS, Bradshaw CS, et al. Transmission and selection of macrolide resistant Mycoplasma genitalium infections detected by rapid high resolution melt analysis. PLoS One. 2012;7(4):e35593.

32. Jensen JS, Bradshaw CS, Tabrizi SN, Fairley CK, Hamasuna R. Azithromycin treatment failure in Mycoplasma genitalium-positive patients with nongonococcal urethritis is associated with induced macrolide resistance. Clin Infect Dis. 2008;47(12):1546-1553.

33. Tagg KA, Jeoffreys NJ, Couldwell DL, Donald JA, Gilbert GL. Fluoroquinolone and macrolide resistance-associated mutations in Mycoplasma genitalium. J Clin Microbiol. 2013;51(7):2245-2249.

34. Shimada Y, Deguchi T, Nakane K, et al. Macrolide resistance-associated 23S rRNA mutation in Mycoplasma genitalium, Japan. Emerg Infect Dis. 2011;17(6):1148-1150.

35. Walker J, Fairley CK, Bradshaw CS, et al. Mycoplasma genitalium incidence, organism load, and treatment failure in a cohort of young Australian women. Clin Infect Dis. 2013;56(8):1094-1100.

36. Couldwell DL, Tagg KA, Jeoffreys NJ, Gilbert GL. Failure of moxifloxacin treatment in Mycoplasma genitalium infections due to macrolide and fluoroquinolone resistance. Int J STD AIDS. 2013; 24(10):822-828.

37. Doherty IA, Padian NS, Marlow C, Aral SO. Determinants and consequences of sexual networks as they affect the spread of sexually transmitted infections. J Infect Dis. 2005; 191 Suppl 1:S42-S54.

38. Kikuchi M, Ito S, Yasuda M, et al. Remarkable increase in fluoroquinolone-resistant Mycoplasma genitalium in Japan. J Antimicrob Chemother. 2014;69(9):2376-2382.

39. Gesink DC, Mulvad G, Montgomery-Andersen R, et al. Mycoplasma genitalium presence, resistance and epidemiology in Greenland. Int $J$ Circumpolar Health. 2012;71:1-8.

40. Chrisment D, Charron A, Cazanave C, Pereyre S, Bebear C. Detection of macrolide resistance in Mycoplasma genitalium in France. J Antimicrob Chemother. 2012;67(11):2598-2601. 
41. Pond MJ, Nori AV, Witney AA, Lopeman RC, Butcher PD, Sadiq ST. High prevalence of antibiotic-resistant Mycoplasma genitalium in nongonococcal urethritis: the need for routine testing and the inadequacy of current treatment options. Clin Infect Dis. 2014;58(5): 631-637.

42. Hay B, Dubbink JH, Ouburg S, et al. Prevalence and macrolide resistance of Mycoplasma genitalium in South African women. Sex Transm Dis. 2015;42(3):140-142.

43. Deguchi T, Ito S, Hagiwara N, Yasuda M, Maeda S. Antimicrobial chemotherapy of Mycoplasma genitalium-positive non-gonococcal urethritis. Expert Rev Anti Infect Ther. 2012;10(7):791-803.

44. Takahashi S, Ichihara K, Hashimoto J, et al. Clinical efficacy of levofloxacin $500 \mathrm{mg}$ once daily for 7 days for patients with non-gonococcal urethritis. J Infect Chemother. 2011;17(3):392-396.

45. Yasuda M, Maeda S, Deguchi T. In vitro activity of fluoroquinolones against Mycoplasma genitalium and their bacteriological efficacy for treatment of M. genitalium-positive nongonococcal urethritis in men. Clin Infect Dis. 2005;41(9):1357-1359.

46. Maeda SI, Tamaki M, Kojima K, et al. Association of Mycoplasma genitalium persistence in the urethra with recurrence of nongonococcal urethritis. Sex Transm Dis. 2001;28(8):472-476.

47. Ito S, Yasuda M, Seike K, et al. Clinical and microbiological outcomes in treatment of men with non-gonococcal urethritis with a 100-mg twice-daily dose regimen of sitafloxacin. J Infect Chemother. 2012;18(3):414-418.

48. Takahashi S, Hamasuna R, Yasuda M, et al. Clinical efficacy of sitafloxacin $100 \mathrm{mg}$ twice daily for 7 days for patients with non-gonococcal urethritis. J Infect Chemother. 2013;19(5):941-945.

49. Hamasuna R, Takahashi S, Kiyota H, et al. Effect of gatifloxacin against Mycoplasma genitalium-related urethritis: an open clinical trial. Sex Transm Infect. 2011;87(5):389-390.

50. Jensen JS, Fernandes P, Unemo M. In vitro activity of the new fluoroketolide solithromycin (CEM-101) against macrolide-resistant and -susceptible Mycoplasma genitalium strains. Antimicrob Agents Chemother. 2014;58(6):3151-3156.

51. Golparian D, Fernandes P, Ohnishi M, Jensen JS, Unemo M. In vitro activity of the new fluoroketolide solithromycin (CEM-101) against a large collection of clinical Neisseria gonorrhoeae isolates and international reference strains, including those with high-level antimicrobial resistance: potential treatment option for gonorrhea? Antimicrob Agents Chemother. 2012;56(5):2739-2742.
52. Hook EW, Jamieson BD, Oldach D, Harbison H, Whittington A, Fernandes P. A phase II, dose ranging study to evaluate the efficacy and safety of single-dose oral solithromycin (CEM-101) for treatment of patients with uncomplicated urogenital gonorrhoea. Sex Transm Infect. 2013;89:A29-A30.

53. Roblin PM, Kohlhoff SA, Parker C, Hammerschlag MR. In vitro activity of CEM-101, a new fluoroketolide antibiotic, against Chlamydia trachomatis and Chlamydia (Chlamydophila) pneumoniae. Antimicrob Agents Chemother. 2010;54(3):1358-1359.

54. Tully JG, Taylor-Robinson D, Cole RM, Rose DL. A newly discovered mycoplasma in the human urogenital tract. Lancet. 1981;1(8233): $1288-1291$.

55. Jensen JS, Hansen HT, Lind K. Isolation of Mycoplasma genitalium strains from the male urethra. J Clin Microbiol. 1996;34(2):286-291.

56. Hamasuna R. Identification of treatment strategies for Mycoplasma genitalium-related urethritis in male patients by culturing and antimicrobial susceptibility testing. J Infect Chemother. 2013;19(1):1-11.

57. Hamasuna R, Osada Y, Jensen JS. Antibiotic susceptibility testing of Mycoplasma genitalium by TaqMan $5^{\prime}$ nuclease real-time PCR. Antimicrob Agents Chemother. 2005;49(12):4993-4998.

58. Touati A, Peuchant O, Jensen JS, Bebear C, Pereyre S. Direct detection of macrolide resistance in Mycoplasma genitalium isolates from clinical specimens from France by use of real-time PCR and melting curve analysis. J Clin Microbiol. 2014;52(5):1549-1555.

59. Vester B, Douthwaite S. Macrolide resistance conferred by base substitutions in 23S rRNA. Antimicrob Agents Chemother. 2001;45(1):1-12.

60. Shimada Y, Deguchi T, Nakane K, et al. Emergence of clinical strains of Mycoplasma genitalium harbouring alterations in ParC associated with fluoroquinolone resistance. Int J Antimicrob Agents. 2010;36(3): $255-258$.

61. Khosropour CM, Manhart LE, Colombara DV, et al. Suboptimal adherence to doxycycline and treatment outcomes among men with non-gonococcal urethritis: a prospective cohort study. Sex Transm Infect. 2014;90(1):3-7.

62. Lewis DA, Chirwa TF, Msimang VM, Radebe FM, Kamb ML, Firnhaber CS. Urethritis/cervicitis pathogen prevalence and associated risk factors among asymptomatic HIV-infected patients in South Africa. Sex Transm Dis. 2012;39(7):531-536.

63. Manhart LE, McClelland RS. Mycoplasma genitalium infection in subSaharan Africa: how big is the problem? Sex Transm Dis. 2013;40(5): $428-430$.
Infection and Drug Resistance

\section{Publish your work in this journal}

Infection and Drug Resistance is an international, peer-reviewed openaccess journal that focuses on the optimal treatment of infection (bacterial, fungal and viral) and the development and institution of preventive strategies to minimize the development and spread of resistance. The journal is specifically concerned with the epidemiology of antibiotic

\section{Dovepress}

resistance and the mechanisms of resistance development and diffusion in both hospitals and the community. The manuscript management system is completely online and includes a very quick and fair peerreview system, which is all easy to use. Visit http://www.dovepress.com/ testimonials.php to read real quotes from published authors. 